\title{
BMJ Global Health Defining global health as public health somewhere else
}

\author{
Nicholas B King (i) , ${ }^{1,2,3}$ Alissa Koski (1) 2,3
}

\begin{abstract}
To cite: King NB, Koski A. Defining global health as public health somewhere else. BMJ Global Health 2020;5:e002172. doi:10.1136/ bmjgh-2019-002172
\end{abstract}

Handling editor Seye Abimbola

Received 18 November 2019 Revised 10 December 2019 Accepted 11 December 2019

Check for updates

\section{(C) Author(s) (or their} employer(s)) 2020. Re-use permitted under CC BY-NC. No commercial re-use. See rights and permissions. Published by BMJ.

${ }^{1}$ Biomedical Ethics Unit, McGill University, Montreal, Quebec, Canada

${ }^{2}$ Epidemiology, Biostatistics and Occupational Health, McGill University, Montreal, Quebec, Canada

${ }^{3}$ Institute for Health and Social Policy, McGill University, Montreal, Quebec, Canada

Correspondence to Dr Nicholas B King; nicholas.king@mcgill.ca

\section{INTRODUCTION}

There are many definitions of global health, ${ }^{1-3}$ but none capture what is truly distinctive about the field. In particular, beyond tautologically emphasising the 'global' nature of its efforts, none properly distinguish 'global health' from 'public health'. ${ }^{45}$

We propose the following definition: global health is public health somewhere else.

Conventional definitions of global health tend to focus on its methods, which are generally indistinguishable from public health, or its aspirations, which are well intentioned but do little to describe what is distinctive about the field. We focus instead on a concept that we believe unifies the field. We offer this definition to encourage reflection on the assumptions that underlie many global health efforts. Apart from its economy of words, our definition has the virtue of directing attention to the why and how, as well as the what of global health. Global health as a field is not distinguished by its aspirations, methods of research and practice, intervention strategies or even geographical area per se, but rather by a particular relationship between its practitioners and its recipients: a person engages in global health when they practise public health somewhere-a community, a political entity, a geographical space-that they do not call home.

Focusing on this relationship invites us to confront the normative dimensions of global health head on. It urges us to ask questions like: Why practise public health somewhere else (rather than at home)? How do we justify practising public health somewhere else? Who has the expertise to practise public health somewhere else and to whom are we accountable when we do so?

Our definition also acknowledges aspects of contemporary global health practice that give rise to critiques, including its inherent colonialism, uncritical faith in Western expertise and technology, lack of accountability and inefficient use of resources. ${ }^{6-8}$ The problems

\section{Summary box}

Many definitions of global health have been offered, but none properly distinguish this field from public health more generally. We propose the following definition: global health is public health somewhere else.

- Our definition encourages consideration of the normative dimensions of global health, and their impact on aspects of training and practice that lead to unintended consequences and critiques.

- Practising public health somewhere else often involves tacit assumptions of an expertise gradient, limited understanding of accountability and inefficient interventions.

with global health as currently practised are not aberrations. They do not result from inadequate methods or lack of good intentions. Rather, they arise directly from the fundamental fact that it is public health somewhere else.

Most communities have pressing health problems at home; why go somewhere else? A common response is that need is greater elsewhere, and we thus have a duty to intervene. There is much to be said in favour of recognising a duty to help those in need outside one's immediate community. Global inequalities in health are stark and pervasive, and rightfully motivate concern on the part of individuals and institutions. The sense of duty to address these inequalities is often driven by deep commitments to social justice, equity and solidarity. As Singer and others have persuasively argued, moral obligations to prevent suffering and death should not end at the borders of one's own community. ${ }^{9-11}$ However, good intentions alone are insufficient to justify acting on populations somewhere else, particularly when the claim of greater need blinds us to unwarranted assumptions about our ability to effectively intervene. While the aspirations behind much global health work are no doubt justified from an ethical perspective, the imperative to 
practise public health somewhere else can often produce unintended-and in some cases harmful—consequences.

\section{EXPERTISE}

The first assumption underlying many global health efforts concerns the capacity to successfully intervene. Global health interventions often implicitly assume an expertise gradient, in which we-a 'we' that is drawn almost exclusively from wealthy countries in the global northhave superior understanding about how best to identify, prioritise and solve pressing health problems somewhere else. Public health problems are often characterised by complex interactions between disease dynamics and societies. Successful interventions require not only expert knowledge of disease dynamics but also the feasibility, efficacy and acceptability of interventions in particular places, among particular populations. The latter requirements are shaped by local culture, social histories and politics that are best known by those who live them, part of an 'information paradox' at the heart of global health efforts. ${ }^{512}$

An assumed expertise gradient is manifest when public health concerns identified by outside parties are presumed to be priorities for local populations. It is manifest when outside parties fail to partner meaningfully with local populations in the development, conduct and evaluation of interventions, as this implies that the partial knowledge held by outsiders is sufficient and ignores vital expertise located somewhere else. In its worst manifestations, students or other individuals with little or no training presume to have greater expertise simply by virtue of coming from somewhere else. This is illustrated most clearly when individuals perform actions somewhere else, including invasive medical procedures, that they are unqualified to perform at home. ${ }^{13}$

The assumed expertise gradient is often accompanied by a perception that problems elsewhere are simpler than those at home. Global health practitioners are often well aware of the social, political and economic complexities of public health problems at home, so much so that they may seem intractable. It is attractive to assume that problems somewhere else will be easier to solve. Why would we assume this? In many cases, this assumption arises from a lack of familiarity with local individuals, institutions, cultures and partner organisations, which allows one to perceive 'somewhere else' as a blank slate for interventions. When coupled with the assumed duty to act, practising public health elsewhere may seem to offer a moral clarity and practical ease that is difficult to find at home. How else could we reconcile our inability to address complex problems at home with a confidence in our ability to solve them elsewhere?

\section{ACCOUNTABILITY}

Public health interventions at home are legitimated through respecting local norms and responding to local structures of accountability. We hold ourselves accountable to local standards because we are expected to be aware of them and we often share them; we accept efforts by peers and institutions to hold us accountable for the outcomes of our interventions because we recognise their moral, cultural and/or legal authority. When we practise public health somewhere else, we are often less familiar with local norms and structures of accountability. This leads to an assumption that-so long as the intention is to help - global health interventions need not be vetted by the individuals and communities they are intended to help.

The accountability gap means that public health efforts somewhere else often reflect home-grown political, economic or ideological priorities, which may lead to research and programmes that are inefficient or unwanted, or worse, unacceptable or harmful to recipient communities. Indeed, many global health programmes are accountable to institutions-philanthropic foundations, governments, regulators, funders, universities, private companies-at home, not elsewhere.

Global health interventions demonstrate a lack of accountability when they ignore the long-term impacts and sustainability of their interventions, and when they fail to take responsibility for negative and unintended consequences as we would be expected to at home. Lack of accountability may be particularly pervasive in short-term global health experiences, whose participants receive little preparation, will not have continued engagement with the recipients of their interventions and will be gone before consequences materialise.

\section{INEFFICIENCY}

A final point concerns the relationship between equity and efficiency. Practising public health somewhere else is especially resource-intensive: transporting people and equipment incurs financial and environmental costs, and additional resources must often be devoted to translation, security, and housing for practitioners and trainees. Increasing demand for academic global health training and 'field experiences' among students from the global north means not only more costs but also more demands placed on individuals and institutions in the global south. Trainees must be supervised, which requires the time and attention of healthcare professionals and community members who would otherwise attend to the needs of patients or other intended beneficiaries of global health. ${ }^{14}$ Increased need may warrant increased costs and resources, but only insofar as they are used wisely and in accordance with local needs. We must thus critically examine the assumption that interventions and programmes motivated by concerns for equity and solidarity do not need to consider efficiency. Along with a duty to help those most in need comes a duty to judiciously consider the justification for these additional costs and resources.

\section{CONCLUSION}

Commenting on international aid, Angus Deaton notes 
The aid endeavor is inspired by the question of what we should do, or by its imperative version that we must do something. Yet this may be precisely the wrong question, and asking it may be part of the problem, not the beginnings of a solution. Why is it we who have to do something? Who put us in charge?... We often have such a poor understanding of what they need or want, of how their societies work, that our clumsy attempts to help on our terms do more harm than good... Negative unintended consequences are pretty much guaranteed when we try. And when we fail, we continue on because our interests are now at stake - it is our aid industry, staffed largely by our professionals, and generating kudos and votes for our politicians - and because, after all, we must do something. ${ }^{6}$

Criticisms of global health echo those faced by international aid and generally target the assumptions that accompany the imperative to act somewhere else, rather than the imperative itself. At a time of rapidly expanding interest in and intensifying critique of global health, our definition encourages greater reflection on the deep-rooted assumptions of the discipline that are often papered over by its lofty aspirations. As Seye Abimbola has noted, the intended beneficiaries of global health would likely define the field very differently from how most of its practitioners do. Ours is a provisional effort by two academics in the global north as a step towards an eventual decolonisation of global health. ${ }^{5}$

We do not believe that all global health efforts are inherently flawed or unjustifiable. Rather, we offer our definition to encourage a more widespread and transparent discussion of the unexamined normative dimensions of global health within academic training programmes and among current practitioners in other settings. To put it simply, we hope that this definition will inspire individuals involved in global health to ask themselves: why practise somewhere else?

Contributors Both authors contributed to all aspects of conception and writing of this article.

Funding The authors have not declared a specific grant for this research from any funding agency in the public, commercial or not-for-profit sectors.
Competing interests None declared.

Patient consent for publication Not required.

Provenance and peer review Not commissioned; internally peer reviewed.

Data availability statement There are no data in this work.

Open access This is an open access article distributed in accordance with the Creative Commons Attribution Non Commercial (CC BY-NC 4.0) license, which permits others to distribute, remix, adapt, build upon this work non-commercially, and license their derivative works on different terms, provided the original work is properly cited, appropriate credit is given, any changes made indicated, and the use is non-commercial. See: http://creativecommons.org/licenses/by-nc/4.0/.

\section{ORCID iDs}

Nicholas B King http://orcid.org/0000-0002-2093-3380

Alissa Koski https://orcid.org/0000-0001-5170-6693

\section{REFERENCES}

1 Koplan JP, Bond TC, Merson MH, et al. Towards a common definition of global health. The Lancet 2009;373:1993-5.

2 Beaglehole R, Bonita R. What is global health? Glob Health Action 2010;3.

3 Campbell RM, Pleic M, Connolly $\mathrm{H}$. The importance of a common global health definition: How Canada's definition influences its strategic direction in global health. J Glob Health 2012;2:010301.

4 Fried LP, Bentley ME, Buekens P, et al. Global health is public health. Lancet 2010;375:535-7.

5 Abimbola S. On the meaning of global health and the role of global health journals. Int Health 2018;10:63-5.

6 Deaton A. The great escape: health, wealth, and the origins of inequality. Princeton University Press: Princeton, 2013.

7 Packard RM. A history of global health: interventions into the lives of other peoples. Baltimore: Johns Hopkins University Press, 2016.

8 Horton R. Offline: is global health neocolonialist? The Lancet 2013;382

9 Benatar SR, Daar AS, Singer PA. Global health ethics: the rationale for mutual caring. Int Aff 2003;79:107-38.

10 Frenk J, Gómez-Dantés O, Moon S. From sovereignty to solidarity: a renewed concept of global health for an era of complex interdependence. Lancet 2014;383:94-7.

11 Singer P. One world: the ethics of globalization. New Haven: Yale University Press, 2002.

12 Hyett S, Marjerrison S, Gabel C. Improving health research among Indigenous peoples in Canada. Can Med Assoc $J$ 2018;190:E616-21.

13 Rosenberg T. The business of voluntourism: do western do-gooders actually do harm? The Guardian, 2018. Available: https://www. theguardian.com/news/2018/sep/13/the-business-of-voluntourismdo-western-do-gooders-actually-do-harm [Accessed 13 sep 2018].

14 Russ CM, Ganapathi L, Marangu D, et al. Perspectives of host faculty and trainees on international visiting faculty to paediatric academic departments in East Africa. BMJ Glob Health 2016;1:e000097. 